\title{
INTERSECÇÃO DA FENOMENOLOGIA DA RELIGIÃO NA MEDIDA E DESMEDIDA DA EXISTÊNCIA PARA A SAÚDE MENTAL EM TEMPOS DE PANDEMIA
}

\author{
Intersection of the phenomenology of religion in the measure and release of existence for \\ mental health in pandemic times
}

\author{
Flavio da Silva Chaves ${ }^{1}$ \\ Crisóstomo Lima do Nascimento ${ }^{2}$
}

\begin{abstract}
RESUMO
A presente pesquisa tem como objetivo apresentar o paradoxo entre a medida e desmedida da existência pelo viés da crise científica enquanto verdade universal ao fenômeno religioso como possibilidade de saúde em tempos de pandemia. Ainda que se admita os paradoxos e antagonismos entre ciência e religião, fé e razão, conjectura-se a possibilidade de a espiritualidade atuar como chave terapêutica na sustentação psíquica do sujeito frente aos dilemas existenciais e contextos traumáticos. A partir da revisão bibliográfica de cunho qualitativo, ponderou-se os antagonismos científicos sob a forma de verdade inequívoca e universal, além de pontuar que a medida e desmedida da existência se dá pelo próprio sujeito. Neste contexto, se apresenta a urgência de uma ciência que leve em consideração a correlação sujeito/objeto e a sua subjetividade para, então, analisar as experiências fenomênicas da religião na saúde mental.
\end{abstract}

Palavras chaves: História da ciência; fenomenologia; pandemia; religião; saúde mental.

\section{SUMMARY}

The present research aims to present the paradox between the measure and excess of existence through the scientific crisis as a universal truth to the religious phenomenon as a possibility of health in times of pandemic. Although the paradoxes and antagonisms between science and religion, faith and reason are admitted, it is conjectured the possibility of spirituality acting as a therapeutic key in the subject's psychic support in the face of existential dilemmas and

\footnotetext{
${ }^{1}$ Mestre em Ciências da Religiões pela Faculdade Unida de Vitória (FUV). Especialização em Psicoterapia Existencial e Gestalt Terapia pelos Institutos Superiores de Ensino do Censa (ISECENSA). Graduação em Psicologia pela Universidade Estácio de Sá (UNESA) e doutorando em Cognição e Linguagem (UENF). Atua como professor do curso superior na Faculdade Batista do Estado do Rio de Janeiro (FABERJ). É psicólogo clínico. Tem experiência na área de Psicologia Clínica em comunidade de risco social. Compõem o Núcleo de Estudos e Pesquisa em Psicologia, Fenomenologia e Filosofias da Existência (NEPPFFE). flavio.chaves.silva@hotmail.com, Orcid 0000-0002-0446-2769.

2 Psicólogo Clínico, Doutor em Educação pela Faculdade de Educação da Universidade Federal Fluminense; Mestre em estudos da subjetividade com ênfase em Fenomenologia pelo Programa de pós graduação em Psicologia da Universidade Federal Fluminense, com graduação, bacharelado e licenciatura em Psicologia pela mesma instituição, pós-graduação em Filosofia e pós-doutorando em Ciências da religião pelo PPG da PUC-Campinas. Professor Adjunto da Universidade Federal Fluminense, vinculado ao Departamento de Psicologia do Pólo Universitário de Campos dos Goytacazes. Professor do PPG em Cognição e linguagem da Universidade Estadual do Norte Fluminense - UENF. Coordenador do Grupo de Trabalho Fenomenologia, Saúde e Processos Psicológicos da Associação Nacional de Pesquisa e Pós-Graduação em Psicologia (ANPEPP). Integrante e membro fundador da Associação Brasileira de Psicologia Fenomenológica - ABRAPFE. É Coordenador do Grupo de Estudos e Pesquisas em Psicologia, Fenomenologia e Filosofias da existência (GEPPFFE) e tem experiência nas áreas de Psicologia Clínica, Fenomenologia, Existencialismo, Hermenêutica e Educação. crisostomoln@gmail.com, Orcid 0000-0001-8764-5220.
} 
traumatic contexts. Based on the qualitative bibliographic review, scientific antagonisms were considered in the form of unequivocal and universal truth, in addition to pointing out that the measure and excess of existence occurs by the subject himself. In this context, there is an urgent need for a science that takes into account the subject / object correlation and its subjectivity to then analyze the phenomenal experiences of religion in mental health.

Key words: History of science; phenomenology; pandemic; religion; mental health.

\section{Introdução}

A presente pesquisa tem como objetivo apresentar o paradoxo entre as ideias de medida e desmedida da existência pelo viés da crise científica enquanto verdade universal ao fenômeno religioso como possibilidade de saúde em tempos de pandemia. Propõe-se, neste entrelaçamento teórico, pontuar que as vivencias não devem ser classificadas e pautadas a partir dos modos biologizantes das ciências naturais (Feijoo 2020). Por outro lado, pensar ciência fora do campo de verificação de verdades fundantes requer uma aproximação dos discursos críticos de se fazer ciência (Feyerabend1977) incutindo, deste modo, o pensamento fenomenológico. A sociedade contemporânea tem vivido os mais profundos dilemas com a perpetuação e classificação de modos de vivência que rotula e estereotipa os seres humanos com o seu respectivo desdobramento na saúde e no ethos cultural e social. Neste sentido, demarca-se na atualidade, um modus operandi da vida, como se fosse possível medi-la a partir das verdades fundantes, numa dicotomização sujeito e objeto. Ao não considerar a subjetividade, perde-se conceitos importantes como a tolerância e o respeito à singularidade do ser, relevantes para temas que atravessam as questões sociais como a questão de gênero, a xenofobia, o preconceito racial e, atualmente, a saúde mental avassalada pelas crises advindas da pandemia (Ornell et al 2020), interesse do referido trabalho.

Logo, para uma perspectiva de saúde mental neste contexto, conjectura-se a hipótese de uma desconstrução conceitual científica segundo os paradigmas da verdade absoluta, inequívoca e objetivante para a discussão de uma ciência fenomenológica em que se atribui novos sentidos a existência. Para tanto, se faz necessário pontuar as discussões relacionadas aos antagonismos conceituais do que seja ciência contrabalançando teorias pelo viés cartesiano e, paralelamente, os seus novos paramentos metodológicos (Feyerabend1977; Chalmers 1993; Pessoa Jr 1993; Roger 1996; Kuhn 2012). Em seguida, refletir sobre a influência de uma ciência que não leve em consideração a subjetividade na medida e desmedida da existência (Feijoo 2020), dissociada da visão sujeito e objeto. Por último, pensar a ciência em diálogo com o fenômeno religioso (Heidegger, 1997; Croatto 2001; Silva 2014; Bello, 2021) para uma 
concepção de homem/mundo na contemporaneidade pontuando, desta forma, a espiritualidade como chave terapêutica na sustentação do self (Xavier 2006; Peres 2007; Santos 2014).

\title{
O percurso da revolução científica e os seus dilemas
}

Iniciaremos nos debruçando sobre a compreensão clássica de ciência, tomada como discurso adequado sobre um objeto pelo sujeito do conhecimento, pautado numa compreensão cindida e dual entre sujeito e objeto do conhecimento. Sendo assim, Chalmers (1993) apresenta a história da ciência numa perspectiva metodológica reducionista que vai do indutivismo ao realismo não-representativo da ciência. No primeiro, a ciência é definida como conhecimento derivado dos dados da experiência, enquanto o segundo apresenta a perspectiva relativista da mesma em sua natureza. Neste sentido, é possível perceber, historicamente, as variáveis existentes no campo científico, desdobrando-se para novos paradigmas na contemporaneidade. Obviamente, não existe a pretensão de invalidar os progressos alcançados até então na solução de diversos problemas e dilemas da sociedade, melhorando a qualidade de vida.

Desta feita, é ingênuo pensar numa ciência fundamentada apenas na mensuração, descartando outros elementos enquanto modos de interpretar o mundo. Segundo Chalmers (1993, p. 19):

\begin{abstract}
Os desenvolvimentos modernos na filosofia da ciência têm apontado com precisão e enfatizado profundas dificuldades associadas à ideia de que a ciência repousa sobre um fundamento seguro adquirido através de observação e experimento e com a idéia de que há algum tipo de procedimento de inferência que nos possibilita derivar teorias científicas de modo confiável de uma tal base. Simplesmente não existe método que possibilite às teorias científicas serem provadas verdadeiras ou mesmo provavelmente verdadeiras.
\end{abstract}

Todavia, considerar a ciência como não fundamento e categorização de uma verdade, não significa desqualificar suas teorias como meras hipóteses. A questão que nos impõe na contemporaneidade e em qualquer tempo é a supervalorização da ciência em detrimento de outros saberes e intervenções. A perspectiva da não supervalorização da ciência enquanto saber privilegiado é apresentado nas discussões de Chalmers que, apropriando-se dos escritos extremados de Feyerabend (1970) citado por Chalmers (1993, p. 20) afirma que o ponto de vista corrente era que “a ciência não tem características especiais que a tornem intrinsecamente superior a outros ramos do conhecimento tais como mitos antigos ou vodu”. Neste sentido, é possível verificar o campo de tensão na natureza das ciências, tendo como foco a crítica ao positivismo lógico e as sugestões metodológicas contemporâneas a partir da teoria do relativismo, enfatizando “a ideia de que o valor das teorias deve ser julgado relativamente aos 
valores dos indivíduos ou grupos que os contemplam [...]” (Chalmers 1993, p. 22). Como afirma o próprio Feyerabend (1977, p. 17) “a ciência é um empreendimento essencialmente anárquico: o anarquismo teorético é mais humanitário e mais suscetível de estimular o progresso do que suas alternativas representadas por ordem e lei” problematizando, desta forma, a absolutização do método científico numa perspectiva positivista.

Nesta trajetória, o filósofo Francis Bacon (1561-1626) adota uma atitude científica contrária às preocupações filosóficas medievais reiterando o fato de que apenas a experiência é fonte fidedigna de conhecimento. O posicionamento é de que o método empirista viesse alcançar alto grau de certeza e irrefutabilidade.

Nosso método, contudo, é tão fácil de ser apresentado quanto difícil de se aplicar. Consiste no estabelecer os graus de certeza, determinar o alcance exato dos sentidos e rejeitar, na maior parte dos casos, o labor da mente, calcado muito de perto sobre aqueles, abrindo e promovendo, assim, a nova e certa via da mente, que, de resto, provém das próprias percepções sensíveis (Bacon, 2020, p. 2).

Tendo como pressuposto a antecipação da mente e interpretação da natureza, Bacon (2020) julga ter alcançado a verdade sobre as coisas, avaliando o conhecimento das épocas anteriores de fantasioso, uma referência aos conceitos científicos pautados em elementos religiosos que até então explicavam o mundo, denominado de Teoria dos Ídolos. Em sua concepção, tais ídolos atuam de modo a obstruir a verdade e o intelecto humano.

Os ídolos e noções falsas que ora ocupam o intelecto humano e nele se acham implantados não somente o obstruem a ponto de ser difícil o acesso da verdade, como, mesmo depois de seu pórtico logrado e descerrado, poderão ressurgir como obstáculo à própria instauração das ciências, a não ser que os homens, já precavidos contra eles, se cuidem o mais que possam (Bacon, 2020, p. 13).

Os ídolos são denominados de 'Ídolos da Tribo', 'Ídolos da Caverna’, 'Ídolos do Foro' e 'Ídolos do Teatro’ e a única maneira de vencê-los é "a formação de noções e axiomas pela verdadeira indução” (Bacon 2020, p. 13). A partir destas noções conjectura-se as limitações da mente e da natureza humana. Desta feita, os Ídolos da Tribo é uma referência a natureza humana e as suas limitações, uma vez que o intelecto humano é semelhante ao espelho que reflete de modo desigual e distorcida a realidade das coisas. Já os Ídolos da Caverna fazem menção ao mito da caverna de Platão, onde dois indivíduos possuem limitações e aberrações quanto a própria natureza e, adjunto, possui uma caverna que impedem a luz da natureza. Devido ao caráter multidimensional das impressões humanas, a mente fica "sujeita a múltiplas perturbações, e até certo ponto sujeita ao acaso” (Bacon, 2020, p. 14). Os Ídolos do Foro dizem respeito a comunicação entre os indivíduos que por sua vez também bloqueia o intelecto. Segundo essa acepção, as palavras conduzem os homens a inúmeras controvérsias e fantasias. 
E, finalmente, Ídolos do Teatro: tais ídolos são provenientes do campo filosófico, cultural e científico.

Após destacar pontualmente as impossibilidades de extrair dos elementos metafísicos qualquer explicação de mundo, estabelece-se o Método Indutivo de Investigação, baseando-se na observação dos fenômenos naturais. Neste contexto, “o que deve ser sobretudo considerado é a matéria, os seus esquematismos, os metaesquematismos, o ato puro, e a lei do ato, que é o movimento” (Bacon 2020, p. 16). Mas seria esta avaliação os parâmetros científicos da modernidade? Jacob Jr. (1993) apresenta a evolução histórica das ciências em sua fase embrionária a novas conjecturas como as “Novas Sociologias da Ciência”. De modo que o seu texto é dividido em quatro partes: a visão recebida da Filosofia da Ciência; a Sociologia da Ciência Funcionalista; a Nova Filosofia da Ciência e, por último, as Novas Sociologias da Ciência. Sendo assim, a visão recebida da Filosofia da Ciência advém da unidade dos métodos da lógica com a visão empirista, onde o conhecimento se funda na observação. Demarca-se, neste ponto, a divisão entre os racionalistas clássicos, preconizando que o conhecimento provém do intelecto; e o positivismo, enfatizando os limites entre a ciência e a metafísica. Logo, a “chamada 'visão recebida' (ou 'ortodoxa') da natureza da ciência se formou a partir das diversas tentativas em definir as teorias científicas a partir da lógica” (Pessoa Jr., 1993, p. 2).

Ressalta-se que, no positivismo lógico, estabeleceram-se importantes discussões entre as sentenças observacionais versus as sentenças teóricas, onde, a partir de 1936, Carnap citado por Pessoa Jr. (1993, p. 2) considera que as "hipóteses científicas em geral não podem ser completamente verificadas, mas somente confirmadas até um certo grau”, inaugurando em 1950, a noção probabilista de grau de confirmação que, segundo Chalmers (1993) é um refino do método indutivista e, de igual modo, refutando a ideia positivista entre observação e teoria enquanto unidade científica. A questão que se impõe é o elemento subjetivação em detrimento da objetificação na ciência em relação a observação do fenômeno.

\footnotetext{
Existem duas suposições importantes envolvidas na posição indutivista ingênua em relação à observação. Uma é que a ciência começa com $a$ observação. A outra é que a observação produz uma base segura da qual o conhecimento pode ser derivado [...]. ... que o que os observadores veem, as experiências subjetivas que eles vivenciam ao verem um objeto ou cena, não é determinado apenas pelas imagens sobre suas retinas, mas depende também da experiência, expectativas e estado geral interior do observador (Chalmers, 1993, p. 47- 51).
}

Ressalta-se ainda, no positivismo lógico, a unidade da ciência, "no sentido de que todos os ramos da ciência devem compartilhar do mesmo método, podendo ser expressos de maneira fisicalista” (Pessoa Jr., 1993, p. 2). Opondo-se a esta visão surge a teoria do falseacionismo de 
Karl Raimund Popper (1902-1994), eminente crítico do Positivismo Lógico e do dogmatismo da razão. Em sua concepção, o conhecimento mais firme da ciência não advém do indutivismo. Segundo a sua teoria, a hipótese científica não se dá pela verificabilidade dos enunciados, mas pelo fato de poder ser falseada ou contrastada pela experiência, a partir do Método HipotéticoDedutivo.

\begin{abstract}
Segundo concepção amplamente aceita - a ser contestada neste livro -, as ciências empíricas caracterizam-se pelo fato de empregarem os chamados 'métodos indutivos'. De acordo com essa maneira de ver, a lógica da pesquisa científica se identificaria com a Lógica Indutiva, isto é, com a análise lógica desses métodos indutivos (Popper, 1972, p. 27).
\end{abstract}

Segundo Pessoa Jr. (1993, p. 2): A ciência não progride por "generalização indutiva", observando fatos e derivando
leis e teorias, mas sim pelo método hipotético-dedutivo: parte-se de uma conjectura
(uma hipótese obtida de uma maneira qualquer) e de hipóteses auxiliares, deduzem-
se suas consequências observacionais, e então comparam-se estas consequências com
observações empíricas. Se houver uma discrepância grande, então a conjectura (ou
talvez uma das hipóteses auxiliares, como salientaram Duhem e Quine) é falseada, e
a ciência progride. Se não ocorrer falseamento, então diz-se que a conjectura
(ou a teoria) foi "corroborada".

Surge, no mesmo cenário do Positivismo Lógico, a teoria da probabilidade de Hans Reichenbach (1891-1953) citado por Pessoa Jr. (1993) considerando que “confirmação ou refutação teriam sempre um grau de probabilidade, e o “problema da indução” de Hume seria resolvido pragmaticamente usando a noção de probabilidade” (Pessoa Jr., 1993, p. 2). Neste contexto, faz-se a distinção entre contexto da justificação, “que trata como a ciência deve ser e que seria assunto da filosofia da ciência" e o contexto da descoberta, "que trataria de como a ciência é na realidade, sendo assunto da história, da sociologia ou da psicologia” (Pessoa Jr., 1993, p. 3). Essa concepção da ciência se consolida em 1950 inaugurando, desta forma, a lógica da ciência, estabelecendo uma distinção entre observação e teoria no campo científico. “A observação é considerada como sendo independente da teoria. Teorias progridem de acordo com critérios racionais: confirmação, falseamento, simplicidade, probabilidade” (Pessoa Jr., 1993, p. 3).

Desta feita, conquanto reconheçamos os feitos magníficos dos teóricos como Galileu Galilei, Isaac Newton e Francis Bacon para a ciência moderna, trazendo rigor de observação dos fenômenos naturais, mudando consubstancialmente os parâmetros de cientificidade, a contemporaneidade exige novos métodos. É o que propõe Thomas Kuhn (2012) com a sua metodologia Novos Paradigmas da Ciência ao enfatizar que o postulado ciência e dogma não se misturam é um mito que necessita ser repensado para a inserção de uma nova metodologia 
do conhecimento científico inferindo, a partir desta premissa, os pressupostos teóricos da Revolução Científica. Sobre isso Barra (2012, p.14) comenta:

\begin{abstract}
De modo sumário, as revoluções científicas são episódios que, segundo Kuhn, dependem da seguinte configuração de acontecimentos sequenciais: ciência préparadigmática (atividades desorganizadas), ciência normal, época de crise, ciência extraordinária, revolução científica e, por fim, um novo período de ciência normal e o consequente reinício cíclico do mesmo percurso. O conteúdo de cada revolução científica é, obviamente, específico de cada ciência particular. Normalmente, após atingir um amplo reconhecimento dos seus efeitos sobre a comunidade científica, as revoluções tornam-se conhecidas pelos nomes de seus principais protagonistas: revolução copernicana, revolução newtoniana, revolução lavoisieriana, revolução darwinista, revolução mendeliana, revolução einsteiniana etc.
\end{abstract}

Sendo assim, “a história da ciência não consiste apenas de fatos e de conclusões retiradas dos fatos. Contém, a par disso, ideias, interpretações de fatos, problemas criados por interpretações conflitantes, erros, e assim por diante” (Feyerabend, 1977, p. 20) elencando, sob este ponto de vista, o aspecto subjetivo do pesquisador nas teorias. Neste sentido, a proposta kuhniana é pensar a ciência em sua bipolaridade se alternando em seu caráter dogmático e revolucionário, estabelecendo polos de tensão necessários para novas revoluções. Nesta direção,

[...] uma certa dose de dogmatismo, embora destinada inicialmente a disciplinar os cientistas a observar o que lhes prescreve o paradigma vigente, é também um aliado indispensável quando se torna inevitável substituir um velho paradigma envolto em anomalias. Somente pessoas profundamente conscientes dos limites de um paradigma podem consistentemente propor a sua substituição. Numa palavra, para Kuhn, não há revolução sem dogmatismo - e vice-versa (Barra, 2012, p. 21).

Logo, o que é científico no contemporâneo? "Ser científico é, entre outras coisas, ser objetivo e ter espírito aberto” (Kuhn, 2012, p. 21). Frente à complexidade do que seja ou não científico vale ressaltar que "a busca por um critério de demarcação científica, distinguindo a ciência da não-ciência, tornou-se uma das questões centrais da filosofia da ciência no século passado, mantendo-se ainda em certa evidência atualmente” (Alves \& Valente, 2020, p. 174). Neste sentido, a tese de Kuhn é que ciência se faz em sua relação com a história denominadas de pré-ciência, ciência normal, crise e revolução científica envolvendo valores cognitivos e extracognitivos na escolha e aceitação de paradigmas (Alves \& Valente, 2020).

Devido ao caráter de imprevisibilidade da ciência, a Revolução Científica se dá quando a resposta para um problema numa dada época não corresponde a situação presente, denominada de crise da ciência. Sendo assim, Alves \& Valente (2020) apresentam três maneiras pelas quais se dão a insegurança e complexidade da ciência para o estabelecimento de um novo paradigma: quando o paradigma presente não consegue resolver os motivos da crise; quando a resistência ao problema em que tanto as abordagens novas quanto as clássicas se mostram 
insuficientes na superação das dificuldades e no surgimento de um novo candidato ao paradigma dominante.

Este último modo de resolução propicia a entrada da área de pesquisa num período denominado 'ciência extraordinária'. Este termo faz referência a um momento de grandes transições, as quais são fundamentais para o desenvolvimento da atividade científica, gerando novos conhecimentos sobre a realidade (Alves \& Valente, 2020, p. 186).

Concomitantemente, o método postulado por Morin (1977) advoga o caráter de relação entre conhecimento e contexto adjunto à sua aplicabilidade nas questões adjacentes a cotidianidade dos entes, considerando o entrecruzamento entre ciência, política e ideologia sem justaposição dominante de um em relação ao outro. Rearticula-se, em seu escrito, a visão de homem, ciência e sociedade numa relação simultânea. Deste modo,

\begin{abstract}
O que é logicamente necessário, dado que todo o conceito remete, não apenas para o objecto concebido, mas também para o sujeito que concebe. Estamos perante a evidência descoberta há dois séculos pelo filosofo-bispo: não existem 'corpos não pensados’. Ora, o observador que observa, o espírito que pensa e concebe, são indissociáveis duma cultura, e portanto de uma sociedade hic et nunc. Todo o conhecimento, mesmo o mais físico, sofre uma determinação sociológica. Existe ern toda a ciência, mesmo na mais física, uma dimensão antropossocial. A realidade antropossocial projecta-se e insçreve-se [sic.] precisamente no cerne da ciência física. (Morin, 1977, p. 15).
\end{abstract}

Sob a égide das "ciências extraordinárias" como metodologia para a covid-19 que passamos a refletir acerca do diálogo entre os novos parâmetros de cientificidade e o fenômeno religioso. Antes, porém, devemos nos atentar para a subjetividade do sujeito enquanto medida existencial para a saúde mental na contemporaneidade.

\title{
Saúde mental na contemporaneidade: entre a medida e desmedida da existência
}

A COVID-19 é nome da doença causada por um vírus chamado SARS-Cov-2, pertencente à família dos coronavírus. Eclodiu na cidade de Wuahan, na China, em dezembro de 2019, afetando o mundo e sendo declarada Pandemia pela Organização Mundial da Saúde (OMS) em 11 de março de 2020. O contexto pandêmico em sua complexidade em todos os âmbitos traz à tona discussões importantes quanto as medidas de prevenção e combate ao novo coronavírus. Obviamente, não se pretende desarticular as medidas protetivas do isolamento social tão necessárias a não propagação do vírus, onde qualquer seguimento deve assumir um compromisso com a saúde pública.

Por outro lado, as questões envolvidas na pandemia não se restringem ao não contágio, mas a outros elementos que agravam as condições psicológicas como a perda de emprego, o 
luto, a ausência de sentido, o medo iminente da morte, podendo ocasionar o Transtorno de Estresse Pós Traumático (TEPT). Kapczinski e Margis (2003) considera o TEPT como um problema de saúde pública, acarretando prejuízos ao indivíduo e a sociedade, apontando para reações como ansiedade, medo, desespero e nos casos agudos, "retraimento da interação social, diminuição da atenção, desorientação aparente, raiva ou agressão verbal, desespero, desesperança, hiperatividade inadequada e pesar incontrolável e excessivo” (Kapczinski \& Margis, 2003, p. 3).

Considerando a possibilidade de a pandemia provocar um estresse agudo, sob qual prioridade os cientistas devem se lançar no combate ao coronavírus: o físico ou o mental? Ornell et al (2020) afirmam que a ciência tem se voltado para os mecanismos fisiopatológicos e subestimado e negligenciado o psicológico e o psiquiátrico. Reitera que, em casos de pandemia, as repercussões psicológicas e psiquiátricas como medo e raiva devem ser levadas em consideração. Segundo os autores,

\footnotetext{
Durante as epidemias, o número de pessoas cuja saúde mental é afetada tende a ser maior que o número de pessoas afetadas pela infecção. Tragédias anteriores mostraram que as implicações para a saúde mental podem durar mais tempo e ter maior prevalência que a própria epidemia e que os impactos psicossociais e econômicos podem ser incalculáveis se considerarmos sua ressonância em diferentes contextos (Ornell et al, 2020, p. 2).
}

O prognóstico nos remete a questões essenciais sobre o modo de prevenir e atuar em tempos de pandemia. A questão é complexa. Os problemas enfrentados estão acima da contaminação do vírus propriamente dito, exigindo novos modos de intervenção e um pluralismo metodológico nas ciências conforme preconizado na epistemologia contemporânea do pensador austríaco Paul Karl Feyerabend (1977). Sendo assim, “a proliferação de teorias é benéfica para a ciência, ao passo que a uniformidade lhe debilita o poder crítico. A uniformidade, além disso, ameaça o livre desenvolvimento do indivíduo” (Feyerabend 1977: 45). Nessa direção, ressalta-se, nas ciências humanas, a crítica quanto a utilização das ciências naturais enquanto parâmetro de medida existencial na psicoterapia que, de modo sucinto, será utilizado em diálogo com o novo campo das ciências modernas, a fenomenologia. Nessa orientção, Feijoo (2020) traz alguns questionamentos que podem nos ajudar neste diálogo com as ciências extraordinárias de Kuhun (2012) adjunto ao pluralismo metodológico nas ciências de Feyerabend (Roger, 1996) para os tempos modernos.

1- No momento em que defendemos o espaço da clínica como lugar que sustenta a possibilidade de conquista da medida existencial, não estaríamos posicionando uma medida como critério que indica o lugar onde ela deve ser alcançada? 2- Estaríamos assim recaindo no que estamos criticando, ou seja, que a teoria é aquela que posiciona como o homem deveria ser e como não deveria ser? 3- Se não é uma medida objetiva 
e se defendemos que não caímos naquilo de onde queremos nos mover, que posição devemos tomar? (Feijoo, 2020, p. 9-10).

Logo, a relação entre a medida e desmedida da existência pelo viés da psicoterapia, considerando os polos de tensão, deve ser pensada pela via não classificatória. Em outras palavras, devido ao caráter da subjetividade humana, é o próprio homem que busca a própria medida de sua existência, de seu modo de estar no mundo. Nesta trajetória, a autora percorre três caminhos como possibilidade para uma intervenção na saúde psíquica contemporânea:

[...] devemos desconfiar da medida que diz como o homem deve se comportar, como se isso fosse algo dado naturalmente, seja pela norma, seja pela interioridade; depois, pensar com cuidado nas verdades postas e, por fim, poder deixar aparecer aquela que está diante de nós. Trata-se de assumir uma atitude fenomenológica em relação às verdades consideradas absolutas. (Feijoo, 2020, p. 11).

Heidegger (2015), enquanto professor da Universidade de Friburgo entre os períodos de 1919 e 1923, engajou-se num projeto audacioso na tentativa de relacionar a vida e a filosofia dissociada do tecnicismo cientifico e da metafisica indagando, neste contexto, a questão do sentido do ser. Para tanto, é indispensável, na definição do ser, abster-se de qualquer preconceito e ideias preconcebidas. Ainda que na concepção aristotélica, platônica e medieval o ser seja definido numa perspectiva universalizante, um ser transcendens, o conceito ainda permanece obscuro, carecendo de novos princípios epistemológicos. “O conceito de ser é indefinível. Essa é a conclusão tirada de sua máxima universalidade” (Hedegger, 2015, p. 39) que não deve ser confundido com os entes que o definem advindo do que se compreende sobre o ser. Sendo assim, "por vivermos sempre numa compreensão de ser e o sentido de ser estar, ao mesmo tempo, envolto em obscuridade, demonstra-se a necessidade de princípio e de se retornar a questão sobre o sentido de 'ser’” (Heidegger, 2015, p. 39).

Indaga-se, nesta perspectiva, acerca da medida e desmedida da existência em tempos de pandemia. Seria a ciência um balizador sobre os comportamentos humanos neste contexto? Se sim, considerando a questão do contágio e a necessidade de isolamento social, sob quais critérios a ciência deve trabalhar? Usando o argumento de Kuhn (2012) de que ciência se faz entre o dogmatismo e a revolução, a pandemia questiona os parâmetros de cientificidade tornando urgente novas metodologias, como aponta Edgar Morin

Ao conferir uma leitura sobre a pandemia do coronavírus e o isolamento social em entrevista ao jornal francês CNRS, o filósofo Edgar Morin explicita que o cenário nos impõe desconstruções: a desconstrução da crença em verdades absolutas na ciência, da obstinação por garantias e certezas, e da pesquisa sem controvérsias (Fronteiras do pensamento, s.p). 
Segundo Morin citado por Fronteiras do pensamento (2020, s.p.), “a ciência é uma realidade humana que, como a democracia, se baseia em debates de ideias, embora seus métodos de verificação sejam mais rigorosos”. O cenário nos impõe pensar e repensar o anarquismo epistemológico de Paul Karl Feyerabend em defesa de um método científico pluralista (Roger 1996), numa postura crítica ao racionalismo enquanto verdade inequívoca e universal que, ao pensar nos argumentos de Feijoo (2020) reduz e classifica a existência. Reitera-se que Feyerabend, Popper, Lakatos e Kuhn são considerados inimigos da ciência pelo fato de propor desconstruções epistemológicas contrárias ao positivismo lógico (Roger 1996). A tese feyerabendiana é pela humanização da ciência, mal interpretado por seus interlocutores. Feyerabend (1993) citado por Roger (1996, p. 233) considera que,

[...] filosofias simples, sejam de um tipo dogmático ou mais liberal, têm seus limites. Não há soluções gerais. Um alargado liberalismo na definição de fato pode ter graves conseqüências, enquanto faz um excelente sentido a idéia de que a verdade é ocultada e mesmo pervertida pelos processos destinados a estabelecê-la. Eu, conseqüentemente, novamente alerto o leitor quanto a que não tenho a intenção de substituir princípios velhos e dogmáticos por outros novos e mais libertários. Por exemplo, não sou nem um populista para quem o apelo ao povo é a base de todo o conhecimento, nem um relativista para quem não há verdades enquanto tais, mas apenas verdades para este ou aquele grupo e / ou indivíduo. Tudo o que digo é que os não-especialistas freqüentemente sabem mais que os especialistas e devem, conseqüentemente, ser consultados, e que os profetas da verdade (incluindo aqueles que fazem uso de argumentos), mais frequente que raramente, são levados por uma visão que colide com os próprios eventos que essa visão deve explorar. [sic]

Nesta direção, anarquismo, nas obras de Feyerabend, significa em primeiro lugar,

[...] oposição a um princípio único, absoluto, imutável de ordem, do que oposição a toda e qualquer organização. Na sua tradução metodológica, não significa, portanto, ser contra todo e qualquer procedimento metodológico, mas contra a instituição de um conjunto único, fixo, restrito de regras que se pretenda universalmente válido, para toda e qualquer situação - ou seja, contra algo que se pretenda erigir como o método, como a característica distintiva, demarcadora do que seja ciência. (Roger 1996, p. 233- 234).

A crítica ao racionalismo perpassa pela dissociação entre conhecimento verificável como verdade fundante na modernidade para aquela de conceitos ricos e dependentes do contexto histórico como vista na Grécia.

Sob esse enfoque, podemos entender a razão criticada por Feyerabend como a faculdade pela qual os padrões de tal tradição se exercem, traduzindo-se em obediência a regras fixas e a padrões imutáveis, estabelecendo e submetendo-se a algo como o método, concentrado, na sua versão contemporânea mais fiel, nas seguintes regras: 1. Só aceitar hipóteses que se ajustem a teorias confirmadas ou corroboradas; 2. Eliminar hipóteses que não se ajustem a fatos bem estabelecidos. (Roger, 1996, p. 235).

Os pressupostos do anarquismo epistemológico seguem, via de regra, um campo metodológico abrangendo aspectos ontológicos, antropológicos e pedagógicos. Nesta 
perspectiva, o mundo não é visto de modo estático e fechado, mas desconhecido e com amplas possibilidades de conhecimento. Sendo assim, a ciência deve conferir sentido ao mundo. Para tanto é necessário admitir

[...] que a coisa e a compreensão de uma ideia correta dessa coisa são, muitas vezes, partes de um único e indivisível processo [...] e que não há fatos nus , estando os fatos sempre sujeitos à contaminação fisiológica e histórico-cultural da evidência [...] (2), tomando a História como um labirinto de interações e (3) propondo que a educação científica de seus atores seja conciliada com uma atitude humanista , libertadora, de vida completa e gratificante, junto à tentativa correspondente de descobrir os segredos da natureza e do homem. (Feyerabend 1977 citado por Roger 1996, p. 236).

Logo,

O conhecimento [...] não é um gradual aproximar-se da verdade. É, antes, um oceano de alternativas mutuamente incompatíveis (e, talvez, até mesmo incomensuráveis), onde cada teoria singular, cada conto de fadas, cada mito que seja parte do todo força as demais partes a manterem articulação maior, fazendo com que todas concorram, através desse processo de competição, para o desenvolvimento de nossa consciência. Nada é jamais definitivo, nenhuma forma de ver pode ser omitida de uma explicação abrangente. (Feyerabend 1977 citado por Roger, 1996, p. 236).

Nesse caso, retomando a discussão no polo de tensão entre medida (métron) e desmedida (hybris) que está sempre presente, a própria medida pode ser encontrada na relação do homem com a arte. Tal como os gregos,

O homem moderno também pode encontrar na arte essa possibilidade de resgatar a medida. No entanto, a arte hoje não tem a força do teatro grego. Além disso, há muita verborragia, muita informação, prescrições e orientações objetivas de como o homem deve proceder para encontrar a medida. (Feijoo, 2020, p. 25).

A crítica imposta na afirmação acima é que as técnicas retiraram as possibilidades e singularidades dos seres humanos. Reitera-se, neste ponto, que a fenomenologia, assunto que nos deteremos adiante, se ocupará da crítica à cisão do sujeito e objeto a partir da subjetividade humana enquanto ciência para a contemporaneidade. Neste método, propõe-se um rompimento com os modos objetivantes e classificatórios da existência enquanto parâmetro de medida para que o homem encontre a sua própria medida existencial na modernidade. Em tempos complexos como a pandemia, qual seria a medida da existência, levando em consideração a crise da ciência e o polo de tensão entre medida e desmedida da própria existência? Apropriamo-nos do argumento de Feijoo (2020, p. 32):

No mundo moderno, o que é mais primário, isto é, o jogo da existência, escurece, abrindo espaço para que as medidas externas se instalem. Assim, a medida transformada em norma estabelece como a vida deve acontecer. A conquista do espaço existencial, que se alia às possibilidades do homem em jogo com suas necessidades, torna-se restrita quando passamos a nos comportar como o mundo diz que deveríamos ser. Então, a vida passou a ser regulada por vários poderes, que foram fortalecidos com o aval da ciência. Quando isso acontece, resolvemos, cada vez mais, a ideia de que o próprio homem desconecta sua medida. 
Nesta perspectiva, passemos a considerar os novos parâmetros de cientificidade em diálogo com o fenômeno religioso como método para uma ciência do humano em tempos de pandemia que, de acordo com Corrêa \& Brojato (2016, p. 1) "sob o enfoque fenomenológico, a experiência religiosa pode ser compreendida como um dos modos da pessoa ser-no-mundo, possibilitando, dessa maneira, a descoberta de sentidos na existência frente à angústia perante o Nada”.

\section{Da fenomenologia ao fenômeno da religião: possibilidades fenomênicas para a saúde mental em tempos de pandemia}

O Método Fenomenológico possibilita uma articulação teórica enquanto possibilidade de intervenção de saúde mental neste tempo tão complexo acometendo a humanidade no mundo inteiro. Esta teoria do conhecimento dissocia-se das leis lógicas e de uma ciência fundamentada na objetificação de mundo, fazendo emergir os elementos subjetivos da experiência vivida (Husserl, 2006; 2014). Neste contexto busca-se a essência do fenômeno, estabelecendo a relação entre objetivismo/subjetivismo enquanto parâmetro de cientificidade moderno que, aliado ao eixo epistemológico da filosofia da religião (Zilles, 1991), relaciona o fenômeno religioso (Bello, 2021; Silva, 2014) como algo inerente ao ser humano, de modo que se reflita sobre o lugar da religião enquanto possibilidade fenomênicas para a saúde mental em tempos de pandemia.

Não é objetivo deste trabalho referendar o pensador alemão Edmund Husserl enquanto base epistemológica para pensar pandemia e saúde mental. Todavia, é quase impossível refletir fenomenologia dissociado daquele que é considerado o seu fundador. Portanto as citações em torno deste autor se circunscrevem no sentido de compreender um novo modo de pensar a ciência e a saúde, considerando os aspectos subjetivos da existência e a religião, não como causa/causal, mas enquanto sentido vivencial que perscruta a estrutura humana. Conjecturamos a hipótese de que estes elementos carecem de um reducionismo de conceitos fundantes para agirem interdisciplinarmente em situações de vulnerabilidade social. Gonçalves e Fernandes (2021) em sua apresentação da obra “O sentido do Sagrado: da arcaicidade à dessacralização”, de autoria da renomada pesquisadora do pensamento de Edmund Husserl e Edith Stein, a Ângela Ales Bello, destacam a singularidade da religião no panorama social, histórico e cultural. 
O termo fenômeno vem do grego fainomenom, significando aquilo que aparece, que se mostra. "Logo, literalmente, Fenomenologia é o estudo do que aparece” (Silva, 2014, p. 31). Em sentido amplo,

A Fenomenologia é uma tentativa de compreensão da essência da experiencia humana, seja ela psicológica, social, cultural ou religiosa, a partir da análise das suas manifestações, que são chamadas fenômenos. É uma tentativa de compreensão não do ponto de vista do observador, mas do ponto de vista da própria pessoa que teve a experiencia. (Silva, 2014, p. 31).

Conquanto se admita os antagonismos que circundam a temática religião, ora como crise outrora enquanto êxito, a partir de renomados expositores tais como Mircea Elíade, Max Sheler, Emile Durkheim, Sigmund Freud e outros, de modo geral, as crenças são consideradas fenômenos humanos. Sendo assim, para Ales Bello, “o uso do método fenomenológico para a análise sobre a história e a cultura humana encontram o seu solo mais propício e profundo justamente no campo da religião” (Gonçalves \& Fernandes, 2021, p. 7). Logo,

O caminho fenomenológico de Angela Ales Bello supõe uma Potência que se autocomunica ao ser humano e o provoca a uma relação, cujo estabelecimento se situa na própria vida, marcada pela sociabilidade, pela produção cultural e por sua própria historicidade. Logo, essa Potência não se movimenta na direção do ser humano sem situar-se historicamente e sem a justa imersão na sociedade e na cultura. Disso resulta que a experiência religiosa tem nas relações sociais e na produção cultural as suas mediações, para que haja o encontro entre o ser humano e a Potência, cujas dimensões são a hylética e a noética, originadas do pensamento de Edmund Husserl, esteira filosófica, ainda que não a única, utilizada por Angela Ales Bello em toda esta obra. (Gonçalves \& Fernandes, 2021, p. 7).

A partir do conceito arqueologia fenomenológica do Sagrado e da arqueologia fenomenológica do Sagrado complexo discute-se a inserção da linguagem religiosa e a encarnação do divino na cultura demarcando, desta forma, a emergência da contemporaneidade em que se configura o antropocentrismo e o cientificismo emergindo o relativismo e o ateísmo e, paralelamente, “uma crítica à sua constituição pela qual se ressalta a experiência religiosa presente na profundidade antropológica e histórica dos seres humanos e não determinada pelas configurações dogmáticas e prescrições morais” (Gonçalves \& Fernandes, 2021, p. 8). Por esse ângulo, a obra de Ângela Bello, nos remete aos aspectos da interioridade ao analisar as manifestações religiosas.

[...] é uma obra que nos faz pensar meditativamente que o sentido do Sagrado não é meramente o cumprimento de prescrições institucionais das religiões, mas a afirmação do encontro da Potência com os seres humanos, compreendidos em sua vitalidade histórico-antropológica e em sua transcendência que realça a esperança do novum, que é próprio da re-ligio. (Gonçalves \& Fernandes, 2021, p. 8).

Posto isto, “a meta da pesquisa fenomenológica é atingir a essência da religião” definida por Gustav Mesnsching (1901-1978) citado por Silva (2014, p. 30) como “a experiência do 
encontro com o Sagrado". Ressalta-se que o foco são as ideias manifestas nas experiências religiosas e não os elementos metafísicos circunscrito a explicação da origem do universo ou do ser.

Por trás das manifestações religiosas, existem ideias que determinam o real significado da experiência para o homem que a experimenta. Ao usarmos o termo ideias, fazemos referência a noções, representações mentais ou padrões de pensamento que norteiam comportamentos e visão de mundo, além de darem sentido às mais diversas experiências de vida. Podemos, portanto, conceituar Fenomenologia da Religião como o estudo das ideias religiosas a partir das suas manifestações. (Silva, 2014, p. 35).

Nessa direção Bello (2021, p. 16) afirma:

De fato, a investigação sobre a interioridade, indispensável para compreender o sentido da experiência religiosa, é necessária, em primeiro lugar, para tratar da questão que se refere ao sentido do humano. Este último não pode ser apreendido "de fora", mas é compreendido a partir de dentro, por meio da análise das nossas vivências.

Como pensar religião e saúde mental em tempos de pandemia? Afastando-se dos conceitos racionalistas sem prescindir destes. É a proposta da Fenomenologia da Religião ao considerar a subjetividade do sujeito, a sua interioridade na compreensão do sentido da experiencia religiosa. Para tanto, Silva (2014) chama a atenção para as expressões epoché e eidética como referencial metodológico da fenomenologia inserindo a subjetividade em detrimento da objetividade no paradigma cientifico tradicional. "Os dois conceitos, epoché e eidética, tornaram-se o principal diferencial da Fenomenologia, pois, enquanto os demais métodos científicos excluíam a subjetividade em favor da objetividade, Husserl sugeriu ser possível compreender o subjetivo, a essência, o eidos” (Silva, 2014, p. 37). E ainda: “A Fenomenologia mudou o foco de análise, afirmando que, independentemente de essa experiencia ser um produto da psique ou um real encontro com o sagrado, o que interessa é compreender o que ela significa para o homem religioso, aquele que vivencia tal experiencia” (Silva, 2014, p. 37).

Nesse ponto de vista, busca-se “a essência da forma do conhecimento, na sua diferença em relação à matéria do conhecimento, e sobre o sentido da diferença entre as determinações, verdades ou leis formais (puras), por um lado, e materiais, por outro” (Husserl, 2014, p. vi). Sobre essência, Husserl (2006, p. 3) comenta:

"Essência” designou, antes de mais nada, aquilo que se encontra no ser próprio de um indivíduo como o que ele é. Mas cada um desses "o quê" ele é, pode ser "posto em idéia". A intuição empírica ou individual pode ser convertida em visão de essência (ideação) - possibilidade que também não deve ser entendida como possibilidade empírica, mas como possibilidade de essência. O apreendido intuitivamente é então a essência pura correspondente ou eidos, seja este a categoria suprema, seja uma particularização dela, daí descendo até a plena concreção. 
Deste modo, numa imbricação entre essência e intuição individual, as configurações e sentidos da existência não se esgotam nos modos unilaterais podendo prescindir delas, mas nas múltiplas possibilidades advindos do campo perceptivo - intuição empírica - numa elaboração representativa entre consciência e objeto.

Intuição empírica, e, em especial, experiência, é consciência de um objeto individual e, como consciência intuitiva, "é ela que traz o objeto à doação": como percepção, ela o traz à doação originária, à consciência que apreende "originariamente" o objeto em sua ipseidade "de carne e osso" (Husserl 2006:4).

Por esse lado,

[...] a abordagem fenomenológica é uma abordagem 'fundante' por ocupar-se do 'fundar' toda e qualquer experiência de mundo e do outro. Sua orientação está na direção da busca de 'modos de ser', de 'maneiras de vivenciar' que fazem cada um de nós, de cada grupo ou nação, universos de experiências 'únicos' e 'singulares' (Holanda 2020:116).

Desta feita, contrariando aos pilares modernos da ciência mediadas por conceitos como empreendedorismo, cérebro, centração e publimetria, considera-se que, a ciência humana não deve seguir critérios das ciências naturais e que, a psicologia e a psicopatologia, devem ser norteadas por caminhos diferentes perpassando por uma abordagem do humano numa perspectiva que permite o estabelecimento de sistemas relacionais (Cláudio 2014). Nesse viés, os argumentos aqui delineados dialogam com a perspectiva biopsicossocial da Atenção à Saúde Mental que, grosso modo, tem como elementos potencializadores os fatores sociais, culturais e emocionais. Assim sendo:

\begin{abstract}
Atenção à Saúde Mental é um campo composto por ações que visam a promoção do bem-estar e da cidadania, cujas práticas transportam o foco da atenção do bem-estar e da cidadania, cujas práticas transportam o foco da atenção aos doentes mentais para uma noção de Saúde ofertada às pessoas não necessariamente enfermas, mas que possam desenvolver os seus potenciais. (Madër \& Holanda, 2017, p. 45).
\end{abstract}

Sendo assim, a ciência se faz ciclicamente: olhar para o objeto, racionalizar o objeto, olhar novamente para o objeto, numa perspectiva de que o objeto nunca se esgota enquanto doador de sentido. Neste ponto reside a renovação científica que, a partir da própria razão, sugere novos parâmetros de análise a começar, enquanto objeto metodológico para a intersecção com o fenômeno religioso, a diferença entre a medicina científico natural e a medicina naturalista. "Enquanto esta última surge, na vida comum do povo, a partir da empina e da tradição ingénuas, a Medicina científico natural surge do aproveitamento de intelecções das ciências puramente teóricas, das ciências da corporalidade humana, desde logo a Anatomia e a Fisiologia” (Husserl, 2008, p. 11) que, tendo como diretriz as ciências fundamentais, explicam a natureza, a biologia e a química. 
Depreende-se, desta questão, o questionamento acerca do porque as ciências do espírito não foi incorporada às ciências da natureza a serviço da humanidade uma vez que, tanto a ciência da natureza e, de modo sobreposto a esta a ciência do espírito, carrega em si elementos da corporalidade humana resguardando, claro, aquilo que as distanciam, circunscrito ao mundo circundante. Deste modo, “o nosso mundo circundante é uma formação espiritual em nós e na nossa vida histórica” (Husserl, 2008, p. 15). Por este ângulo, a ciência prescinde dos elementos fundantes para uma cultura científica sob os ideais de infinitude e, respectivamente da humanidade, uma vez que esta é criadora da cultura.

Cultura científica sob ideias de infinitude significa, por conseguinte, um revolucionamento da cultura no seu todo, um revolucionamento do inteiro modo de ser da humanidade enquanto criadora de cultura. Ela significa, também, um revolucionamento da historicidade, a qual é, agora, história do desfazer-se da humanidade finita no fazer-se humanidade de tarefas infinitas (Husserl, 2008, p. 24).

Zilles (1991), tendo como eixo de análise a filosofia da religião, ao mesmo tempo que apresenta a religião como crença em um poder sobre-humano associada a sentimentos e práticas adjacentes de tal crença, reitera o fato de a mesma pertencer a natureza e a estrutura humana o que pressupõe, em nossa análise, o seu lugar nas discussões em tempos tão conturbados como os que vivemos atualmente. Obviamente é preciso estipular as diferenciações entre o discurso religioso, a religião, a filosofia da religião e o fenômeno religioso para não perpetuar um discurso fundante e dogmatizante. O primeiro se concentra na realidade da transcendência numa perspectiva de revelação e redenção que permeia a vida. Na religião, as expressões dos atos espirituais e criações culturais do homem. Já a filosofia da religião se ocupa da sistematização crítica dos dados e, o fenômeno religioso, do sentido último da pessoa, da história e do mundo, na visão do homem religioso (Zilles, 1991; Silva, 2014).

Desta feita, na intersecção entre ciência e fenômeno religioso deve-se manter o devido distanciamento dos discursos religiosos, mas, sincronicamente, da análise de dados numa postura crítica da filosofia da religião. Se para a filosofia da religião o objeto de estudo é o absoluto a partir das origens e o conteúdo dos fatos da experiência suscitando o interminável debate se é possível a interlocução entre razão e religião, para a fenomenologia da religião o que importa é o significado do fato religioso para o Homo Religiosus, a partir dos fenômenos religiosos (documentos, testemunhos, etc.). O seu objetivo é buscar o sentido e significado da religião para o ser humano (Zilles, 1991; Rocha, 2010).

Do mesmo modo que a filosofia da religião, o fenômeno religioso tem as suas interfaces de análise subdivididas na teologia, centrada nos aspectos dogmáticos da fé, na apologética que busca a defesa da verdade sob as lentes de determinada doutrina e a própria filosofia da religião 
conforme descrita anteriormente (Rocha 2010). Dada a complexidade do tema, a fenomenologia da religião, expressão usada primeiramente pelo holandês e historiador Pierre Daniel Chantepie de la Saussaye (1848-1920) em oposição ao termo vigente de religiões comparadas e, depois, também pelo holandês Gerardus van der Leeuw (1890-1950) se apropriam da fenomenologia filosófica de Husserl, propondo um método de compreensão da experiência religiosa em divergência ao método unilateral de descrição que se detinha apenas na “análise das suas linguagens ou dos seus meios de manifestação: os fenômenos” (Silva, 2014, p. 30).

Neste sentido, para entender a linguagem religiosa (símbolo, mito, rito),

[...] é necessário partir da experiência do sagrado que a própria linguagem quer comunicar. Do contrário, trabalha-se sobre termos sem seu correlato real na vida. Mesmo que a finalidade da vivência religiosa seja transcendente (por enquanto, 'o sagrado'), trata-se de uma experiência humana, própria do ser humano e condicionada por sua forma de ser e pelo seu contexto histórico cultural (Croatto, 2001, p. 41).

Não é uma visão do observador para o observado conforme postula o empirismo e as suas deduções. Mas, tendo como eixo a própria experiência, é aquele que vive a experiência religiosa em suas múltiplas formas que pode sinalizar o seu sentido constituinte e constituído. Para tanto, numa possível relação entre ciência e religião, tal fenômeno deve ser analisado a partir de sua historicidade temporal. Heidegger (1997; 2014) explora esta tese tanto na análise do cristianismo a luz do entrelaçamento teórico entre o pensamento agostiniano e as ciências do espirito quanto em seu estudo da fenomenologia da vida religiosa. No primeiro, diz que “quando Deus se revelou na realidade histórica (história da salvação), é retirado do significado teórico, em Platão, e entra no contexto da experiência. Nesse ponto está a origem da consciência histórica” (Heidegger 1997, p. 17). Quanto ao segundo diz: “nós caracterizamos a filosofia e a religião sob o conceito geral do histórico: ‘filosofia e religião são fenômenos históricos”” (Heidegger 2014, p. 32), circunscrita ao espaço-temporal, tal como a ciência.

Ciência é uma relação de proposições válidas atemporalmente. O processo da introdução ocorre contrariamente no tempo, e é cada vez dependente do estado histórico-factual da ciência etc. Pode-se dizer o mesmo para a filosofia e para a religião. Elas também estão subordinadas (unterstehen) ao desenvolvimento histórico. (Heidegger 2014, p. 32).

De que modo o fenômeno religioso pode ajudar na resiliência tornando-se fonte de saúde? A partir da quebra de paradigma dos enunciados científicos como verdade fundante e universal conforme visto anteriormente e, ao mesmo tempo, considerando os modos de estar no mundo; uma vez que, na psicopatologia, ramo da ciência que estuda os fenômenos do adoecimento mental, reitera-se que as experiências e os modos de estar no mundo podem se 
tornar fontes potenciais de adoecimento (Dalgalarrondo, 2008). De modo sincrônico é o ser, e apenas o ser, em sua singularidade e recursos adjacentes a sua experiência com o mundo, pode encontrar a medida e desmedida da própria existência (Feijoo 2020) para lidar com a facticidade da vida.

A partir dessas reflexões somos convocados a assumirmos uma postura crítica sobre os critérios de cientificidade contemporânea, principalmente no que diz respeito ao conceito de saúde e doença, situando-as no modo de existir no mundo, no sentido do ser e não como algo apenas analisado a partir do aparelho biológico; o que, via de regra, conduz o mesmo a uma postura mais humanizada frente ao sofrimento psíquico do indivíduo. Essa postura humanizada e terapêutica visa conduzir o indivíduo ao seu modo mais próprio de ser, que é o sentido de cuidar na psicoterapia existencial:

\begin{abstract}
Cuidar, fenomenológico-existencialmente, quer dizer se ocupar e se preocupar em oferecer àquele que está sendo cuidado as condições para que ele desenvolva e faça crescer as suas genuínas e autênticas maneiras de ser. Cuidar ou curar é cultivar condições para que um homem possa encontrar a sua maneira mais própria de ser homem. A saúde, de um ponto de vista existencial, não é só quanto meu organismo é supostamente saudável, mas também o quanto a minha mobilização como pessoa, no meu existir, tem um sentido para mim (Dichtchekenian, 2011, p. 273).
\end{abstract}

Nesta direção, podemos pensar o cruzamento entre o psicoterapêutico existencial e o fenômeno religioso em suas múltiplas perspectivas fenomênicas, mas sempre no contexto de significância na experiencia fática da vida depreendendo desta e também diferenciando, o experimentar, o experimentado e o afirmar-se daquilo que é experienciado, dissociados de pressupostos científicos e delimitado ao histórico. “O que importa é extrair da experiência fática da vida os motivos para a compreensão da própria filosofia. É desta compreensão própria que obtemos a tarefa total de uma fenomenologia da religião” (Heidegger, 2014, p. 34). Sob este aspecto Xavier (2006, p. 188), aponta que existe uma coesão entre o arquétipo da imagem divina para o arquétipo do self segundo a abordagem junguiana. Sendo assim, "tocar os aspectos religiosos da psique é o próprio objetivo da terapia” pois

\footnotetext{
A integração de tais imagens, através da atitude de religio, tem dois efeitos principais: traz um significado à experiência e à própria vida, e produz fé e esperança [...]. Isto porque as imagens arquetípicas trazem em si, por suas características, um fator organizador e curador - dado também pela questão do sentido e significado inerentes a elas (Xavier, 2006, p. 189).
}

Numa revisão de literatura sobre religiosidade, espiritualidade e psicoterapia, Peres e outros (2007, p. 189) afirmam que “a maioria das abordagens psicoterápicas articula percepção, memória e sistemas de crenças dos indivíduos durante o processo terapêutico”. Comprova-se por meio dessa pesquisa que "a experiência religiosa deixou de ser considerada fonte de 
patologia e, em certas circunstâncias, passou a ser reconhecida como provedora do re-equilíbrio e saúde da personalidade” (Peres, 2007, p. 140). Mas, a que se deve essa mudança de postura? Justamente pelo fato de as pesquisas apontarem para o fator positivo das crenças na saúde psíquica. A maioria dos estudos, apontado por Peres (2007, p. 140) “mostrou que envolvimento religioso e espiritualidade estão associados com melhores índices de saúde, incluindo maior longevidade, habilidades de manejo e qualidade de vida, assim como menor ansiedade, depressão e suicídio”. Dada a relevância do tema, Gallup (1995) citado por Peres (2007) apresenta o perfil da comunidade religiosa americana reiterando que,

O interesse no estudo do papel da religiosidade, espiritualidade e práticas psicoterapêuticas em saúde se dá por diferentes razões socioeconômicas e clínicas. Por exemplo, em culturas industrializadas como a americana, 96\% da população acredita em Deus ou em um espírito universal, 75\% reza regularmente, 42\% frequenta serviços religiosos regularmente, $67 \%$ é membro de algum corpo religioso local, $67 \%$ afirma que a religião é muito importante em suas vidas e $63 \%$ acredita que seus médicos deveriam falar com seus pacientes sobre sua fé espiritual (Peres, 2007, p. 142).

No Brasil, ainda que haja um "potencial religioso sincrético expressivo e alta prevalência de praticantes de religiosidade/espiritualidade - apenas 7,3\% não têm religião” (Peres, 2007, p.144), existe uma carência de pesquisas que contemplem a relação espiritualidade e psicoterapia na dimensão dos conflitos existenciais. Atualmente, as relações conflituosas e amistosas entre ciência e religião, fé e razão, e também o impacto da religião sobre a saúde tem despertado o interesse acadêmico. Sob a crença de que com o avanço da ciência e da razão os fenômenos religiosos desapareceriam, Almeida-Moreira e Lucchetti (2016) trazem um panorama das pesquisas despontando a importância e relevância do tema na articulação ciência e espiritualidade em oposição a crença da secularização da religião pelo racionalismo. Deste modo, no Brasil,

\begin{abstract}
95\% dos brasileiros declaram ter religião, 83\% consideram religião muito importante para suas vidas e $37 \%$ frequentam um serviço religioso pelo menos uma vez por semana. Ao contrário do que se imagina, o nível educacional, a renda e a raça não se associam de modo independente a indicadores de religiosidade. Em linha com o sincretismo brasileiro, 10\% frequentam mais de uma religião (Almeida-Moreira \& Lucchetti, 2016, p. 54).
\end{abstract}

Santos \& Guimarães (2014) em seus estudos sobre Søren Aabye Kierkegaard (18131855), Carl Gustav Jung (1875-1961) e Carl Ransom Rogers (1902-1987) apresentam a dimensão espiritual na psicoterapia. O seu conceito de espiritualidade dissocia-se do conceito teológico de espiritualidade. Assim, para Kierkegaard, o homem está perdido em sua própria identidade, devendo se arriscar para ganhar o eu. “A espiritualidade está no ato de perceber essa 
necessidade. A perda do eu é vista como estreiteza por fechar-se no finito. A estreiteza é falta de primitividade, e, ao despojar-se dela, o homem castra-se espiritualmente” (Santos \& Guimarães, 2014, p. 909). Logo, o trabalho terapêutico "será o de ajudar o outro a resgatar a primitividade, a reconhecer-se em suas escolhas, restabelecendo a relação não só consigo mesmo, mas também com o mundo, ou seja: resgatar a fluidez, o movimento do existir" (Santos \& Guimarães, 2014, p. 910).

Na concepção roggeriana o homem é um ser holístico. É um devir, potência, tendência atualizante, sempre buscando seu ser possível. A proposta, nesta visão, é o encontro como caminho para saborear a totalidade e a inteireza do vivido. “A realização está na restauração da unidade e integração do indivíduo” (Santos \& Guimarães, 2014, p. 920). Nesse processo encontra-se a espiritualidade. Uma vez que o homem tem a tendência à realização, “a terapia tem o papel de propiciar condições necessárias ao crescimento, ou seja, dar suporte para que o cliente possa resgatar a força e o poder do pleno desenvolvimento” (Santos \& Guimarães, 2014, p. 920), constituindo, assim, a dimensão espiritual. Depreende-se dessas observações,

[...] a necessidade de desenvolver o humano e suas próprias forças, afirmando que a psicoterapia é possível devido à existência de uma força integradora que permite ao homem ser fiel ao seu imperativo do projeto de sua existência, não somente resolvendo problemas, mas constituindo-se. [...] a terapia propicia o desenvolvimento do self, ao facilitar o exercício da estrutura eu-tu que se atualiza com novas experiências dialógicas que exigem esforço. [...] A dimensão espiritual facilita uma maior interiozação e reflexão sobre o viver. [...] O sentir-se religado tem valor absoluto, não pela referência a uma divindade concreta, senão pela experiência de estar inserido numa realidade holística que o transcende e o sustenta (Santos \& Guimarães, 2014, p. 922- 923).

A heterogeneidade do tema quanto aos atravessamentos históricos científicos, as demandas contemporâneas oriundas da pandemia e a urgência de novas metodologias no enfrentamento da crise, interpõem-se, no campo da saúde, a necessidade de conhecimentos transversais e interdisciplinares que levem em consideração o sujeito que sofre.

\begin{abstract}
A interdisciplinaridade surge como um dos principais desafios da prática em saúde contemporânea. Se, por um lado, a especificidade é necessária para apurar os diagnósticos e o tratamento das doenças, por outro, sua exclusividade encobre o sujeito que sofre. No campo da Saúde Mental, o desafio está também presente: se precisamos conhecer a psicopatologia, precisamos também trabalhar com as perspectivas de vida de cada sujeito atendido. Se há um sofrimento singular, também há determinantes sociais para sua formação (Madër \& Holanda, 2017, p. 38).
\end{abstract}

Entre paradoxos e antagonismos, seja na história da ciência, seja no campo religioso ou na própria medida da existência, a questão é que a vida acontece no aqui e agora impondo-nos a urgência de entender os contextos culturais e intervir de modo assertivo. O que buscamos 
demonstrar é a experiência religiosa fenomênica como constituinte de sentido para o homus religiousus.

\section{Considerações finais}

Reitera-se nesta pesquisa a crise da ciência e os seus pressupostos teóricos para uma intervenção mais assertiva no mundo pandêmico. Diante disto, salienta-se que, em termos existenciais, no polo de tensão entre medida e desmedida da existência, contrariando os postulados positivistas da ciência, a própria medida pode ser encontrada através dos princípios da arte e não da técnica que, em sua essência, retira as possibilidades e singularidade do humano. Assumimos a hipótese de que, para a inserção da arte e, desta forma, das experiencias religiosas enquanto sustentação do self em tempos de crise, seja necessária uma revisão epistemológica dos parâmetros científicos considerando os aspectos subjetivos da existência em detrimento dos modos objetificados de verdade universal e modelos de saúde que priorizam o físico dissociado do seu contexto social, histórico e cultural.

Concomitantemente, considerando que a medida e desmedida da vida se dá pelo próprio sujeito, tal vivência não deve mensurado pelas classificações métricas advindos do mundo tecnificado. Tendo como referência o pluralismo metodológico, tendência do novo paradigma cientifico da contemporaneidade, reitera-se a multidimensionalidade do existir e, consequentemente, pleiteia-se uma ciência que contemple os mais variados fenômenos da vida.

Nesta direção, de modo sucinto, foi apresentada a psicoterapia existencial enquanto caminho para uma ciência humanizada em tempos pandêmicos numa articulação com as experiências religiosas, vistas sob a ótica da fenomenologia da religião. Nesta perspectiva, sugeriu-se a redução de conceitos e estereótipos conforme dados, para que se abstraia novas significações frente a dor, tendo como objeto de pesquisa os sentidos das manifestações religiosas para o homus religiosus. Ressalta-se que, fenomenologicamente, diante da ruptura eu-tu e da necessidade de novas significações do ser-no-mundo, seja possível novas interpretações a partir de mecanismos que levem em consideração a subjetividade humana, a saber, a espiritualidade enquanto promotora de bem estar.

Ainda que os autores considerem a pesquisa relevante para novas configurações da ciência em tempos pandêmicos, a mesma deixa em aberto temas caros a relação religião/espiritualidade sob a ótica da saúde, estudos ainda incipientes no Brasil. E ainda, os impactos do fechamento por decreto dos serviços religiosos sob a saúde mental, considerados não essenciais. 


\section{REFERÊNCIAS}

ALVES, M. A. Valente, A. R. (2020), A estrutura das revoluções científicas de Kuhn: uma breve exposição. Griot : Revista de Filosofia, Amargosa - BA, v.20, n.1, :173-192, fevereiro.

BACON, F. Novum organum. Tradução e notas de José Aluysio de Andrade. Disponível em: <http://www.dominiopublico.gov.br/download/texto/cv000047.pdf> Acesso em 30 set. 2020.

BARRA, E. S. O. Apresentação. In: KUHN, Thomas. (2012), A função do dogma na investigação científica. Organizador: Eduardo Salles O. Barra; tradução: Jorge Dias de Deus. Curitiba : UFPR. SCHLA.

BELLO, A. A. (2021). O sentido do Sagrado: da arcaicidade à dessacralização. Acervo eletrônico. Paulus. Recuperado em <https://docero.com.br/doc/x5vx0ee> em 18 mai. 2021.

CHALMERS, A. F. (1993), O que é ciência afinal? Tradução de Raul Filker. Editora Brasiliense. Disponível em: <https://www.nelsonreyes.com.br/A.F.Chalmers_O_que_e_ciencia_afinal.pdf> Acesso em: 25 set. 2020.

CLÁUDIO, V. Nota de abertura. In: TEIXEIRA, José A. Carvalho (Org.) (2014), Actas do Colóquio 100 anos da 'psicopatologia geral' de Karl Jaspers. ISPA. Disponível em: <http://loja.ispa.pt/sites/default/files/users/3/actas_karljaspers.pdf> Acesso em: 19 nov. 2020.

CORRÊA, D. A. Brojato, H. C. (2016), Experiência religiosa e saúde: uma perspectiva fenomenológica. Revista Científica UMC, Mogi das Cruzes, v. 1, n. 1.

CROATTO, J. S. (2001). As linguagens da experiência religiosa: uma introdução à fenomenologia da religião. Tradução de Carlos Maria Vasquez Gutierrez. São Paulo: Paulinas. Coleção Religião e Cultura.

DALGALARRONDO. (2008), Psicopatologia e semiologia dos transtornos mentais. 2. ed. Porto Alegre: Artmed. Disponível em $<$ http://pablo.deassis.net.br/wpcontent/uploads/Psicopatologia-e-semiologia-dos-transtornos-mentais-Paulo Dalgalarrondo.pdf > Acesso em: 30 nov. 2015.

DICHTCHEKENIAN, N. Saúde e fenomenologia. In: BLOISE, Paulo (Org.). (2011), Saúde Integral: a medicina do corpo, da mente e o papel da espiritualidade. São Paulo: Editora Senac : 268 .

FEIJOO, A. M. L. C. Hibris y psicoterapia como posibilidad de resgate de la medica existencial. In: Feijoo, A. M. L. Lessa, M. B. M. F. (Org.). (2020), Fenomenologia e práticas clínicas III. 1. ed. Rio de Janeiro: IFEN.

FEVERABEND, P. (1977). Contra o método. Tradução de Octanny S. da Mota e Leonidas Hegenberg. Rio de Janeiro: F. Alves. (Metodologia das ciências sociais e teoria da ciência)

Fronteiras do pensamento. (2020), As certezas são uma ilusão por CNRS / Le Journal por Francis Lecompte. Entrevista a Edgar Morin. Disponível em: https://www.fronteiras.com/entrevistas/edgar-morin-as-certezas-sao-uma-ilusao. Disponível em: 09 mai. 2020. 
GONÇALVES, P. S. L. Fernandes, M. L. Apresentação. In: Bello, A. A. (2021). O sentido do Sagrado: da arcaicidade à dessacralização. Acervo eletrônico. Paulus. Recuperado em <https://docero.com.br/doc/x5vx0ee> em 18 mai. 2021.

HEIDEGGER, M. Estudios sobre mística medieval. Traducción de Jacobo Muñoz. México: Fondo de Cultura Económica, 1997. (Sección de obras de filosofia).

HEIDEGGER, Martin. Fenomenologia da vida religiosa. Tradução de Enio Paulo Giachini, Jairo Ferrandin, Renato Kirchener. 2. ed. Petrópolis, RJ: Vozes; Bragança Paulista, SP: Editora Universitária São Francisco, 2014. (Coleção Pensamento Humano).

HEIDEGGER, M. (2015). Ser e tempo. Tradução revisada e apresentação de Márcia Sá Calvacante; posfácio de Emanuel Carneiro Leão. 10. ed. Petropólis, RJ: Vozes; Bragança Paulista, SP: Editora Universitária São Francisco, 2015.

HOLANDA, A. F. (2011), Gênese e histórico da psicopatologia fenomenológica. In: V. Angerami-Camon (Org). Psicoterapia e Brasilidade (p: 115-160). São Paulo: Cortez Editora.

HUSSERL, E. (2008), A crise da humanidade europeia e a filosofia. Tradução e introdução de Pedro M. S. Alves. Covilhã: Lusofia Press.

. (2006), Idéias para uma fenomenologia pura e para uma filosofia fenomenológica: introdução geral à fenomenologia pura. Tradução Márcio Suzuki. Aparecida, SP: Idéias \& Letras.

KAPCZINSKI, F.; Margis, R. (2003), Transtorno de estresse pós-traumático: Transtorno de estresse pós-traumático: Transtorno de estresse pós-traumático: critérios diagnósticos critérios diagnósticos. Rev Bras Psiquiatr, (Supl I):3-7.

KUHN, T. (2012), A função do dogma na investigação científica. Organizador: Eduardo Salles O. Barra; tradução: Jorge Dias de Deus. Curitiba: UFPR. SCHLA.

MADER, B. J.; Holanda, A. F. (2017), Atenção à saúde mental e atenção psicossocial: aproximações e distinções na conceituação e na oferta assistencial. In: Faria, N. J.; Holanda, A. F. (Org.) Saúde mental, sofrimento e cuidado: fenomenologia do adoecer e do cuidar. Curitiba: Juruá (Coleção Saúde e Psyquê).

MENDLOWICA, E. A sociedade contemporânea e a depressão. Disponível em < http://www.uva.br/trivium/edicao1/artigos-tematicos/4-a-sociedade-contemporanea-e-adepressao.pdf > Acesso em: 14 Mai. 2016. : 42-52.

MOREIRA-ALMEIDA, A. Lucchetti, G. (2016), Panorama das pesquisas em ciência, saúde e espiritualidade. Cienc. Cult. vol.68 no.1 São Paulo.

MORIN, E. (1977). O método: a natureza da natureza. Tradução de Maria Gabriela de Bragança. Portugal: Publicações Europa-América LDA.

ORNELL, F. et al. (2020), Pandemia de medo e Covid-19: impacto na saúde mental e possíveis estratégias. Revista debates inpsychiatry. 
PERES, J.F.: et al. (2007), Revisão de literatura: Espiritualidade, religiosidade e psicoterapia. Rev. Psiq. Clín. 34, supl 1 : 136-145.

PESSOA JR, O. (1993), Filosofia \& sociologia da ciência. Aula ministrada na disciplina de HG-022 Epistemologia das Ciências Sociais do curso de Ciências Sociais da Unicamp, CLE. Disponível em: <http://opessoa.fflch.us:br/sites/opessoa.fflch.us:br/files/Soc1.pdf> Acesso em: 03 dez. 2020.

PPPPER, K. R. (1972), A lógica da pesquisa científica. Tradução de Leonidas Hegenberg e Octanny Silveira da Mota. São Paulo: Editora Cultrix.

ROCHA, A. (2010), Introdução à filosofia da religião: um olhar da fé cristã sobre a relação entre a filosofia e a religião no pensamento ocidental. São Paulo: Editora Vida.

ROGER, A.C.K.: Feyerabend e o pluralismo metodológico. (1996), Cad.Cat.Ens.Fis., v.13, n. 3: :231-247.

Santos, E. A. Guimarães, C. (2014), A dimensão espiritual na psicoterapia. Revista Eclesiástica Brasileira/Faculdade de Teologia/Instituto Teológico Fransciscano, v. 74, n. 296, Petrópolis. : 905-924.

SILVA, C. (2014), Fenomenologia da religião: compreendendo as ideias religiosas a partir de suas manifestações. São Paulo: Vida Nova.

XAVIER, M. (2006), O conceito de religiosidade em C.G. Jung. PSICO, Santa Catarina, v. 37, n. 2, : 183-189.

ZILLES, U. (1991), Filosofia da Religião. São Paulo: Paulus. 